\title{
Successful management of arterial bleeding complicating endoscopic ultrasound-guided cystogastrostomy using a covered metallic stent
}

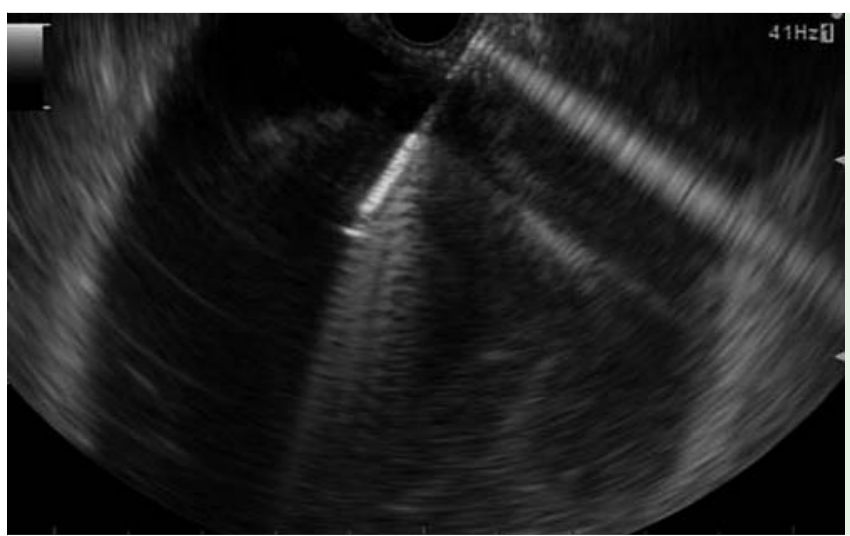

Fig. 1 A pancreatic pseudocyst in a 56-yearold woman, resistant to conservative management, punctured from the stomach under realtime endoscopic ultrasound (EUS) imaging.

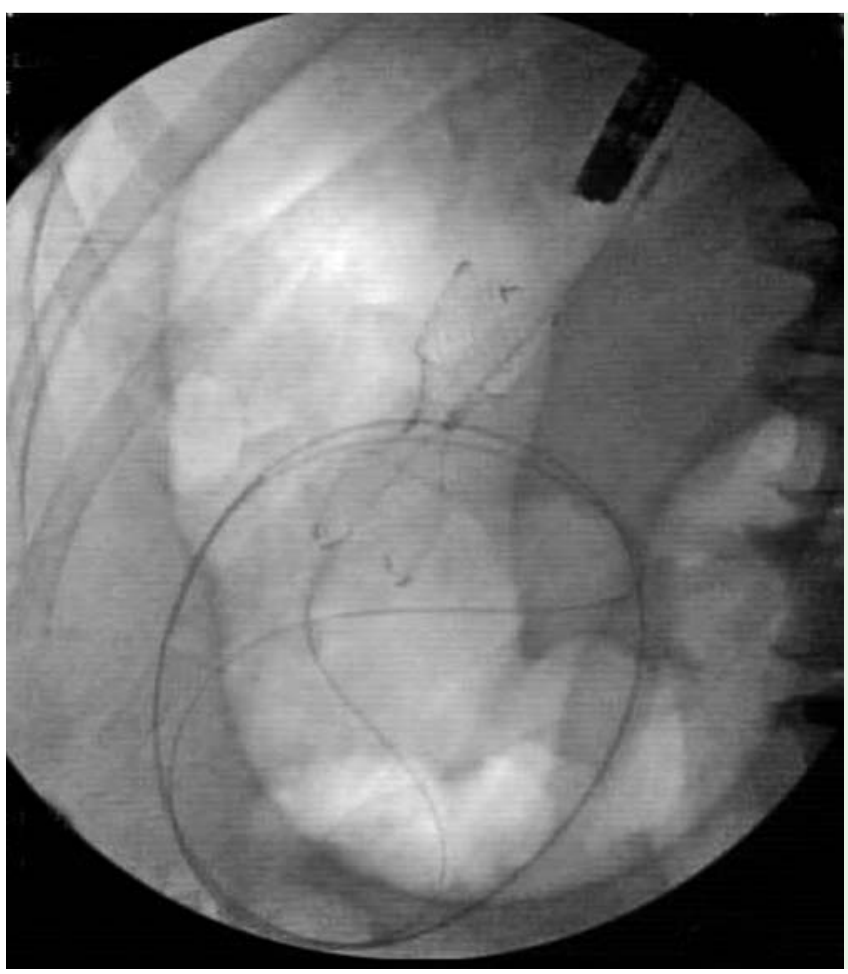

A 56-year-old woman with a symptomatic pancreatic pseudocyst refractory to conservative treatment was referred to us for endoscopic ultrasound-guided pancreatic pseudocyst drainage (EUSPPD). EUS showed a $12-\mathrm{cm}$ cyst near the pancreatic body and tail. The cyst was punctured using a 19-gauge fine needle aspiration (FNA) needle from the stomach under EUS imaging, after careful examination of the intervening vessels with Doppler function ( $\bullet$ Fig. 1 ). A guide wire was coiled within the cyst, followed by dilation of the fistula with needle- knife cautery and a 10-mm balloon. However, on deflation of the balloon, arterial blood was seen spurting from the fistula ( Fig.2). The balloon was reinflated to tamponade the fistula for another 5 minutes to achieve temporary hemostasis. Deflation of the balloon again resulted in arterial bleeding. Attempts to locate the exact bleeding point failed due to the brisk bleeding as well as cystic fluid gushing from the fistula. Therefore, we placed an esophageal, fully covered self-expandable metallic stent (FCMS; $18 \mathrm{~mm} \times 60 \mathrm{~mm}$, Bonastent, Standard Sci-Tech, Seoul,

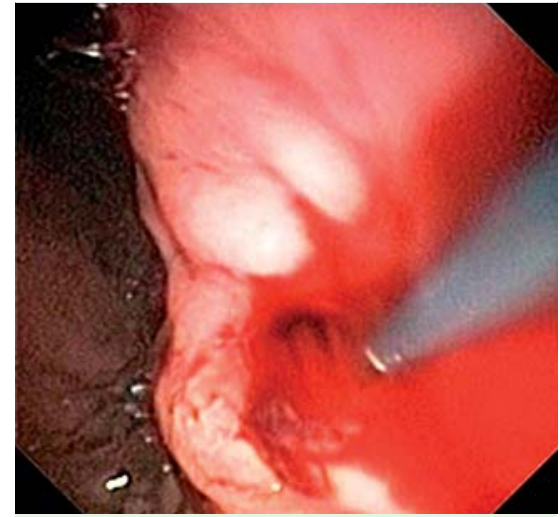

Fig.2 After initial dilation using a $10-\mathrm{mm}$ balloon, spurting arterial blood was seen along with gushing cystic fluid.

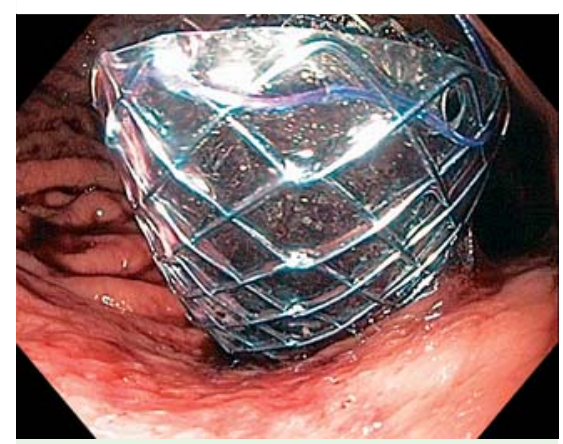

Fig. 4 Hemostasis achieved with mechanical tamponade.

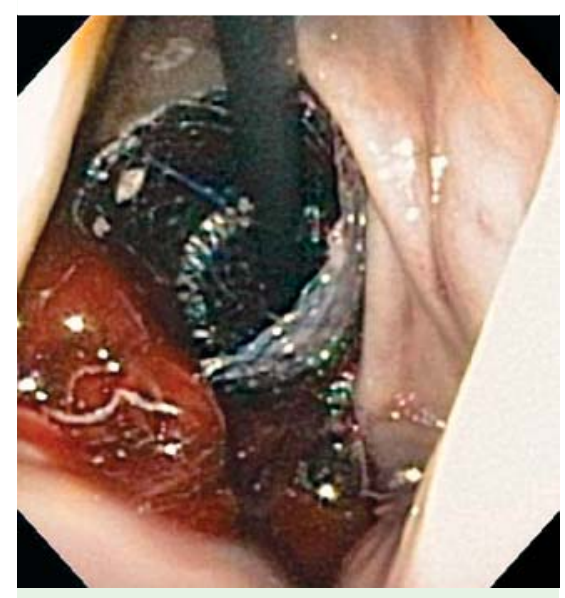

Fig. 5 Retroflexed internal view of the pseudocyst showed a large blood clot but no active bleeding.

Korea) across the cystogastrostomy to tamponade the bleeding vessel, which led to successful hemostasis Fig. 3 and - Fig.4). Inspection of the cyst cavity 
showed a blood clot without active bleeding ( $\bullet$ Fig. 5). The patient remained stable after the procedure and the stent was removed 1 month later with resolution of the pseudocyst.

EUS-PPD is a well-established and minimally invasive alternative to surgery for the management of symptomatic pancreatic pseudocysts [1]. A needle puncture under EUS with Doppler function should theoretically allow avoiding puncturing the adjacent major vessels. However, one study reported that active bleeding occurred in $5.3 \%$ of patients during EUSPPD [2]. In the present case, inability to locate the exact bleeding point made it difficult to carry out thermocoagulation or clipping. An esophageal FCMS was then deployed at the cystogastrostomy, resulting in tamponade and immediate hemostasis. Several papers have reported use of an FCMS at the cystogastric fistula for better drainage $[3,4]$ and closure of the perforation [5]. Our experience shows that the FCMS can also be used for hemostasis in a bleeding cystogastrostomy.
Endoscopy_UCTN_Code_TTT_1AS_2AD

Competing interests: None

T. Iwashita, J. G. Lee, Y. Nakai, J. B. Samarasena, K. J. Chang

H.H. Chao Comprehensive Digestive Disease Center, University of California Irvine, Orange, California, USA

\section{References}

1 Varadarajulu S, Lopes TL, Wilcox CM et al. EUS versus surgical cyst-gastrostomy for management of pancreatic pseudocysts. Gastrointest Endosc 2008; 68: 649-655

2 Will $U$, Wanzar C, Gerlach R et al. Interventional ultrasound-guided procedures in pancreatic pseudocysts, abscesses and infected necroses - treatment algorithm in a large single-center study. Ultraschall Med 2011; 32: 176-183

3 Talreja JP, Shami VM, Ku J et al. Transenteric drainage of pancreatic-fluid collections with fully covered self-expanding metallic stents (with video). Gastrointest Endosc 2008; 68: 1199-1203
4 Berzosa M, Maheshwari S, Patel KK et al. Single-step endoscopic ultrasonography-guided drainage of peripancreatic fluid collections with a single self-expandable metal stent and standard linear echoendoscope. Endoscopy 2012; 44 (Suppl. 05): 543-547

5 Iwashita T, Lee JG, Nakai $Y$ et al. Successful management of perforation during cystogastrostomy with an esophageal fully covered metallic stent placement. Gastrointest Endosc 2011; 76: 214-215

\section{Bibliography}

DOI http://dx.doi.org/

10.1055/s-0032-1310067

Endoscopy 2012; 44: E370-E371

(c) Georg Thieme Verlag KG

Stuttgart · New York

ISSN 0013-726X

Corresponding author

J. G. Lee

101 The City Drive

Building $23 \mathrm{C}$

Orange

California 92868

USA

Fax: +714-456-5820

jglee@uci.edu 